\title{
Cambios en los métodos de selección documental en los sistemas de información digital en las televisiones
}

\author{
Jorge Caldera Serrano * \\ Pilar Arranz Escacha **
}

Artículo recibido:

22 de agosto de 2012.

Artículo aceptado:

18 de enero de 2013.

\section{RESUMEN}

Se analiza y describe el contexto en el que se enmarca la selección documental en los archivos de televisión, para mostrar los principales cambios habidos en los últimos años a tenor de la puesta en marcha de las redacciones digitales y, por tanto, de los sistemas de información digital audiovisual. Se describe cómo estas modificaciones le han dado un papel cada vez más preponderante al periodista en materia de selección y qué parámetros se estaban teniendo en cuenta hasta ahora -coste, espacio, etc.- que ya han sido superados por las nuevas formas de hacer en las televisiones.

* Universidad de Extremadura, España. jcalser@alcazaba.unex.es

** Accenture en Antena 3 TV, España. maria.arranz.escacha@accenture.com

INVESTIGACIÓN BIBLIOTECOLÓGICA, Vol. 27, Núm.60, mayo/agosto, 2013, México, ISSN: 0187-358X. pp. 15-26 
Palabras clave: Selección documental; Archivos de televisión; Información audiovisual; Gestión documental; Información digital.

\begin{abstract}
New documentary selection methods arising from digital information systems employed in television. Jorge Caldera-Serrano and Pilar Arranz-Escacha

The contextual framework of selection of documentaries for broadcast in television is described and analyzed in order to show the key changes this process has undergone in recent years driven largely by widespread digitization of audiovisual information. These changes have afforded journalists a more central role in the selection of documentary materials, as factors such as cost and space, which were once fundamental, become less important in current television production processes.
\end{abstract}

Keywords: Selection Documentary; Archives TV; Audio-visual Information; Document Management; Digital Information.

\title{
OBJETIVO, MÉTODO Y ESTRUCTURA
}

L a selección documental siempre se ha tomado como una de las principales labores de los documentalistas. Una tarea altamente delicada que incluye una parte subjetiva importante, ya que además de las posibles líneas y normas que ofrezca la institución, la decisión será tomada por un documentalista atenido a sus conocimientos y a su entorno social y laboral. Sin embargo, la selección es sin lugar a dudas una operación delicada, de carácter intelectual y en cierta medida individual, que marca el contenido de la colección que se custodia. Y esto es algo más difícil cuando se trata de un audiovisual, y muy especialmente en televisión, donde coexisten realidades que dificultan el trabajo, como son el gran volumen de material y la necesaria rapidez de la labor documental.

El presente trabajo desea mostrar cómo ha cambiado el contexto en el que se realiza la selección en las cadenas televisivas y cómo se han modificado ciertas fórmulas y hábitos a tenor del cambio del paradigma de trabajo. Es imposible seleccionar en lo digital de la misma manera que se realizaba en lo 
analógico, donde los problemas espaciales y económicos exigían rutinas mucho más drásticas y decisiones más dramáticas.

Este trabajo se basa especialmente en la experiencia profesional, donde se han podido detectar cambios en las formas de hacer la selección y en cómo los periodistas quieren ser mucho más protagónicos en el proceso de selección. La observación como método es fundamental para ver los cambios en la selección, aunque también son significativos los datos cuantitativos, como el aumento (en proporción) de horas, lo cual se conserva en la colección del material audiovisual. Pero no es sólo la observación la que nos lleva a estos datos, sino también el contacto con profesionales de diferentes medios de comunicación, quienes cuantifican las impresiones detectadas y determinan este cambio en el sistema digital.

Para detectar los cambios hemos contactado y analizado los medios televisivos españoles tanto del ámbito nacional como autonómico, siempre y cuando hubieran creado y asimilado las formas digitales de producción en sus sistemas de trabajo.

Respecto a la estructura cabe indicar que, por organización, se ha querido incidir en elementos fundamentales para entender los cambios producidos en la selección, analizando quién la realiza, la importancia que tiene la selección para conservar el acervo cultural de un pueblo y de una institución, y por qué se selecciona. Y en lo que se refiere a la selección, se termina luego con el análisis pormenorizado de los cambios generados por los sistemas digitales de información.

\section{¿POR QUÉ SELECCIONAR EN TELEVISIÓN?}

Las televisiones son empresas que trabajan veinticuatro horas al día, siete días a la semana, y trescientos sesenta y cinco días al año; emiten constantemente, durante horas y horas, y producen una gran cantidad de información. El volumen es increíble y la necesidad de separar aquello que es útil de lo que no lo es se traduce en un problema de no siempre fácil solución.

Debe quedar claro que no todo el material audiovisual que entra en las televisiones es útil, y que incluso tal cantidad podría paralizar la validez del servicio de documentación si se conservara todo el material. Tanta cantidad de información colapsaría el servicio de documentación.

Por todo ello es necesario realizar una selección sobre el material emitido y sobre aquél con el cual se han realizado estas producciones. Un par de minutos de un informativo puede tener detrás varias horas de grabación que deberán ser visualizadas y analizadas para determinar si dicho material cuenta con valor potencial para su futuro uso. 
Importante pregunta que cuenta con una respuesta clara, aunque ésta dependerá del medio de comunicación y de sus normativas internas o de sus formas de trabajo.

Lo habitual es que sea el documentalista audiovisual quien decida si un material será conservado definitivamente, temporalmente, o borrado, y siempre tendrá en cuenta las directrices marcadas por las unidades de documentación.

Estos criterios pueden ser más o menos exactos, pero la realidad es que los documentalistas cuentan con un amplio margen de maniobra para la toma de decisión acerca de la selección de dicho material.

Los documentalistas fijarán los criterios de selección atendiendo a las necesidades periodísticas reales y potenciales, presentes y futuras de la cadena, y tomando en cuenta el uso que los periodistas hacen de las imágenes.

Los periodistas a los que esta capacidad les haya sido otorgada por la dirección de la cadena podrán determinar qué imágenes van a ser conservadas. Esto implica una comunicación explícita con el Departamento de Documentación de que dichas imágenes no serán borradas, decisión que habrá sido tomada por el Servicio de Documentación.

\section{Conservando EL PATRIMONiO AUDiOvisuAL}

El ejercicio de selección es sin duda una parte complicada dentro de la labor que desarrollan los documentalistas de los medios de comunicación. Dicha selección cuenta con parámetros que lo especifican como un medio público o privado. La motivación para la selección y conservación del material audiovisual puede variar de forma sustancial.

Conviene señalar que los servicios de documentación existen para gestionar la información, para poder reutilizar en el futuro dicho material y optimizar así los gastos de producción. Por lo tanto la selección se realiza para conservar material que pueda ser posteriormente útil para futuras obras audiovisuales (Póveda, Caldera, Polo, 2010).

Una vez que tenemos clara la primera motivación, legítima sin lugar a dudas, la selección debe realizarse teniendo en cuenta otra serie de parámetros, por ejemplo la necesidad de conservar el patrimonio audiovisual de la cadena como el acervo cultural patrimonial de un país.

Las colecciones audiovisuales de una empresa conservarán, en todos los casos de televisiones públicas y autonómicas, el material que ha sido emitido 
por parte de la cadena, al mismo tiempo que se conservará una parte del material no emitido, que corresponderá a aquél que se considere más relevante.

Y todo ello partiendo de una realidad: la inexistencia de normativas legislativas regulatorias importantes, salvo la que señala que el material audiovisual emitido debe conservarse por un periodo de seis meses, y en formato VHS, debido a potenciales requerimientos legales.

Por lo tanto, los criterios de conservación de las cadenas de televisión deberían tener presente que con su decisión están definiendo las colecciones que conformarán el acervo cultural audiovisual de un pueblo. Partiendo de esta premisa, la conservación será mucho mayor en las cadenas públicas que en las privadas, debido a que éstas deben garantizar el acceso a la información por parte de los ciudadanos.

Tanto es así que TVE cuenta con una normativa reguladora sobre criterios de selección, en los que una parte importante de dichos criterios intenta marcar la necesidad de conservar material audiovisual como valor patrimonial para la cadena y para el país.

El acervo cultural audiovisual está presente en las colecciones de todos los medios de comunicación, y aunque estas cadenas fueran privadas debieran tener presente que gran cantidad de su material tiene un valor histórico real que podrá ser explotado comercialmente en el futuro.

Las colecciones audiovisuales son los grandes olvidados y aunque la Federación Internacional de Archivos de Televisión como la UNESCO lleva a cabo propuestas -en el primer caso- y programas -en el segundo- para garantizar la salvaguarda de las colecciones audiovisuales a nivel mundial, la conservación de este patrimonio cuenta con graves problemas.

Especialmente importante es el costo de conservación de este material, sobre todo para muchos países en vías de expansión, o aquellos que realmente cuentan con problemas mucho mayores que la conservación del material audiovisual.

Otros problemas son los relacionados con la concienciación de la necesidad de conservar estas colecciones, y también la de tener controlada tanta cantidad de material en tantos soportes distintos que evolucionan de una forma trepidante. Problema aparte son los derivados de la conservación física del material audiovisual, soportes que en muchos casos ya cuentan con graves problemas de conservación por su rápida degradación química. No todos los formatos ni todos los soportes deben ser almacenados de la misma manera, más bien deben contar con dependencias diferenciadas para el almacenamiento tanto de los soportes analógicos como de los digitales (Saavedra, 2011). Puede ampliarse la información sobre preservación audiovisual en la publicación de Síntesis (Caridad et al., 2011). 
Hay que ser conscientes de la necesaria conservación del patrimonio audiovisual, y de que es importante la existencia de una legislación que la regule, sin dejarle a la buena voluntad de cada televisión la preservación del material con criterios comunes para toda nuestra sociedad.

\section{HABLEMOS DE CRITERIOS}

Seleccionar es discriminar, identificar aquellos elementos que son y serán útiles de los que no cuentan con valor para nuestros usuarios o no se enmarcan en las políticas de selección de la empresa en el marco de la conservación patrimonial.

Identificar criterios de clasificación es realmente complicado porque éstos son marcados por cada unidad de documentación. No obstante sí contamos con algunas voces especialmente interesantes que nos pueden servir de guía para marcar estas pautas y criterios.

La Federación Internacional de Archivos de Televisión es sin ningún género de dudas la entidad de carácter supranacional más importante e interesante en materia de normalización en lo referente a archivos audiovisuales, y muy especialmente, los televisivos.

La FIAT/IFTA señala que se conservará todo lo emitido y todo lo grabado para emisión, por lo menos durante cinco años. Este primer criterio es algo complejo, ya que conservar la emisión parece algo lógico e incluso interesante, pero la conservación de todo el material con el cual se ha generado la información carece de interés, y provoca sin lugar a dudas ruido documental en el momento de la recuperación. Por lo tanto sí parece lógico conservar todo el material emitido, para siempre y por siempre, y discriminar aquel material que sea más útil de entre el resto de aquél que ha sido generado para producir dicha emisión.

Además de este primer criterio, la FIAT (Handford, 1986) nos muestra una serie de parámetros o guías que no dejan de ser grandes "cajones" en los cuales incluir el material que debe conservarse, a saber:

- Material sobre Historia y Desarrollo de Televisión, incluye realizaciones artísticas y técnicas, nuevas técnicas de televisión y ejemplos relevantes de técnicas existentes.

- Material en el que aparezcan personas que tienen interés histórico (deporte, entretenimiento, drama, política, ciencias, etcétera).

- Acontecimientos de interés histórico (en todos los campos) incluidos aquellos momentos en los que un programa de televisión en directo sea historia por sí mismo. 
- Materiales de interés sociológico, como aspectos de la vida contemporánea, obras, documentales y entretenimiento ligero.

- Material que muestre objetos, como obras de arte, edificios, maquinaria y equipamiento, etcétera.

- Material que muestre lugares geográficos, especialmente aquellos que se encuentren en periodo de desarrollo.

- Los programas individuales o series de programas que pueden ser de utilidad para futuros recopiladores de programas o que reflejen retrospectivamente la obra de un artista importante y para exhibir nuevamente programas de todo tipo de producción.

La FIAT/IFTA, como otras cadenas de televisión, señala que la decisión del borrado de material debería ser tomada por un equipo interdisciplinar, lo que supondría una descarga para el documentalista en su toma de decisión sobre la selección individual acerca de cada material.

Pero esto es absolutamente imposible. Estos grupos de trabajo pueden llegar a marcar pautas pero no a tomar la decisión sobre qué seleccionar del material audiovisual.

Otra declaración de buenas intenciones sobre los criterios de preservación es la realizada por García y Lucas (1987), la cual señala los siguientes criterios:

- Conservar la información tomando en cuenta el interés de los usuarios reales y potenciales.

- Seleccionar la esencia de la información, lo cual no tiene por qué ser siempre lo publicado o lo emitido.

- Seleccionar noticias definitivas, no rumores o noticias potenciales.

- Evitar la redundancia en la selección de la noticia.

- Seleccionar los medios y fuentes más fiables para hacer el análisis de la selección.

- Contrastar los datos para verificarlos antes de hacer la selección.

- Darle prioridad a la selección de noticias de análisis profundos y no a las superficiales.

- No seleccionar noticias banales.

- Seleccionar en equipo, ya que puede ser útil tanto para un colectivo como para otro.

- Proveer que los mecanismos de selección sean determinados por los índices de obsolescencia de datos.

- Hacer una revisión continua del fondo documental. 
- Establecer los diferentes criterios por medio de políticas claras de selección.

Mabel Giménez (2007) señala que los principales motivos por los que se debe fijar una política de selección son:

- Reducir el componente subjetivo. El ejercicio de la selección sin control no deja de ser un acto subjetivo del documentalista que realiza la labor, con una política clara dicho componente subjetivo será al menos encauzado.

- Afrontar de manera coherente el volumen del material generado. Sería idóneo poder conservar todo el material que se genera, pero como esta idea no deja de ser una utopía que desde el punto de vista de la recuperación documental además cuenta con escaso valor, se deben seleccionar aquellos recursos que sean los más adecuados posible para las necesidades de nuestros usuarios.

- Justificar la rentabilidad de la conservación y del tratamiento documental del material seleccionado.

Caldera y León (2010) sostienen que es complicado hacer entender que la conservación, custodia y análisis del material va en beneficio de la entidad, por lo que si existe una política de selección no será necesario negociar, renegociar y discutir con la dirección de forma permanente. Y también que hay que reglamentar la eliminación del material, y describir cómo va a ser destruido el material audiovisual, que en muchos casos es único y seguramente irrepetible, por lo cual se debe marcar el proceso así como su registro.

Cabe reiterar que los elementos necesarios para crear una política clara de selección es algo que seguirá tras determinar los siguientes parámetros (Giménez, 2007):

- El entorno empresarial.

- Las necesidades de los usuarios.

- La adecuación del archivo.

- El material objeto de selección.

\section{Conservando en el CONTEXTO Digital}

La accesibilidad, la facilidad de manejo y el mayor conocimiento por parte 
digitales hacen que las formas de hacer, entender y acceder a los contenidos hayan cambiado de forma vertiginosa, al igual que se han producido cambios al contar con la información de forma directa, en la terminal, sin necesidad de hacer grandes consultas, ni de recurrir a intermediarios.

Antes el documentalista decidía sobre la conservación y el almacenamiento de prácticamente la totalidad de la información. Ahora los periodistas manejan mucha más información, por lo que también deciden en mayor medida qué material es necesario conservar tomando en cuenta los criterios periodísticos. Por tanto el cambio de accesibilidad ha provocado también cambios importantes sobre quién decide qué es lo que se conserva. El periodista se ha convertido ahora, de verdad, en una pieza fundamental, con quien siempre se ha de contar en los sistemas digitales (anteriormente era el periodista quien no estaba muy interesado en la toma de dicha decisión por lo tedioso del proceso de visionado y la selección que se tenía que hacer del material en analógico).

Otro cambio generado en la conservación se deriva de los costos de almacenamiento y custodia. Adquirir y conservar material analógico (cintas, carcasas de varios tipos de soportes y formatos...) implicaba un costo elevado para las empresas audiovisuales, tanto así que uno de los motivos por los cuales se seleccionaba material era la reutilización del soporte para la nueva grabación de productos. Esto ha cambiado; los sistemas de almacenamiento y conservación son mucho más baratos y más manejables, y esto ha provocado un importante aumento en el número de horas que se conservan. Cuanto más cantidad de material audiovisual se tenga en el archivo, más material se les podrá facilitar a los usuarios para que sean ellos los que decidan su validez. Aunque conservar por conservar nunca es la solución, y siempre se contará con el grave inconveniente del ruido documental que pueden provocar muchas consultas con idénticos o parecidos resultados al contar con mucho material de características parecidas.

Esta facilidad y abaratamiento de los costos se ha traducido en el hecho de que muchas empresas hayan dejado de realizar los compactados temáticos y onomásticos, para qué realizarlos si se podrá localizar dicha información con varios clics de ratón. El soporte ha dejado de tener importancia, cada vez más lo importante es la información, y especialmente su accesibilidad. Al usuario le da igual dónde -físicamente- esté la información, le interesa que ésta le sea accesible por medio de la intranet corporativa a la cual se pueda acceder. Esto ha generado que se conserve una gran cantidad de brutos de rodaje, muchos de ellos de dudosa validez e importancia.

Y el mayor cambio que se ha producido, sin lugar a dudas, y que debiera haberse tratado en primer lugar, es que la selección no se realiza como 
un paso previo a lo visionado, sino que se realiza durante el análisis de los contenidos. Anteriormente se visionaba todo y se decidía qué material iba a ser útil y se describía. Ahora se conserva -y se almacena- una gran cantidad de información y después, durante el visionado, se describirá de manera más pormenorizada aquello que puede interesar para el archivo definitivo; mejor dicho, para estar en nuestro gestor de base de datos con una descripción y asignación de metadatos mucho más pormenorizada. Pero el material no descrito también está en las librerías digitales de información audiovisual, y se puede acceder a él por medio de escaletas, partes de grabación, etc., pero no por la descripción documental.

Sin duda este cambio cuenta con ventajas e inconvenientes. La principal ventaja es que al conservar mayor producción el acervo cultural de la cadena queda garantizado en mayor cuantía, lo cual soluciona un gran problema que era la eliminación de material audiovisual, que en la mayor parte de los casos -salvo material procedente de terceros: productoras, agencias...- significaba la destrucción de material único y en cierta manera irrepetible.

También existen inconvenientes para este modelo: al no estar todo el material descrito mucho de éste es irrecuperable. Material que no está descrito no es recuperable, y la realidad es que el material descrito por los documentalistas cuenta con peculiaridades y características que lo hacen infinitamente más rico para su recuperación y por lo tanto para su uso posterior. Frente a esto también contamos con otro material no descrito por profesionales de la documentación, por lo que la asignación de metadatos asociados -no tantos como se quisieran- no cuenta con criterios documentales ni con control terminológico. Cabe entonces recordar el problema del ruido documental provocado por un aumento importante de los materiales en el archivo de audiovisuales, sobre todo cuando mucho de lo que hay en ellos es irrelevante, y en muchos casos inútil para los usuarios.

Conviene señalar en último lugar que este aumento en la conservación, y por lo tanto en horas de material audiovisual, debería aumentar el número de profesionales dedicados al análisis de tales materiales. La tónica es el ajuste de plantillas y no la expansión, por lo que se espera que con la mejora de la tecnología gran parte del material que ahora no se está analizando de forma documental pueda ser descrito por mecanismos automáticos (Caldera, 2008).

\section{CONCLUSIONES}

Los cambios asociados al nuevo paradigma de trabajo basados en las plataformas digitales, tanto en la producción de noticias (redacción) como en su 
almacenamiento y conservación por medio de los servicios de documentación (sistemas de información audiovisual digital), serían:

- Aumento en el número de materiales conservados, al ser sus costos menores y los problemas espaciales prácticamente inexistentes.

- Por el motivo anterior el periodista cuenta con gran cantidad de material para realizar una consulta y por tanto tener acceso a la información.

- El periodista está mucho más implicado en la toma de decisión de la selección de material, lo que se deriva de la facilidad de acceso dada la reducción de tiempo en la plataforma digital y la mayor concienciación de la necesidad de conservar buen material en los archivos audiovisuales de la cadena.

- El análisis documental del material audiovisual se realiza sobre aquel material que sólo sea relevante según el criterio del documentalista, no obstante se conservan materiales que no han sido analizados.

- El material no seleccionado no es eliminado del archivo digital, sino que podrá ser accesible mediante otras formas de descripción, como escaletas o partes de grabación.

\section{Reconocimientos}

Este trabajo ha sido financiado por la Junta de Extremadura (Consejería de Educación, Ciencia y Tecnología) y el Fondo Social Europeo dentro del plan de apoyo a las actuaciones de los Grupos de Investigación inscritos en el catálogo de la Junta de Extremadura. GR10019.

\section{REFERENCIAS BIBLIOGRÁFICAS}

Caldera-Serrano, J. (2008), "Changes in the management of information in audio-visual archives following digitization: current and future outlook", en Journal of Librarianship and Information Science, vol. 40, núm. 1, pp. 13-20.

Caldera-Serrano, J.; León-Moreno, J. A. (2010), “Marketing analysis of the web-based commercialization of television audiovisual files: opportunities and implications", en Investigación Bibliotecológica, vol. 24, núm. 52, pp. 217-235. 
Caridad Sebastián et al. (2011), Documentación audiovisual: nuevas tendencias en el entorno digital, Madrid, Síntesis.

García Gutiérrez, Antonio Luis; Lucas Fernández, Ricardo (1987), Documentación automatizada en los medios informativos, Madrid, Paraninfo.

Giménez Rayo, Mabel (2007), Documentación audiovisual de televisión: la selección del material, Gijón, Trea.

Hanford, A. (1986), "Normas recomendadas y procedimientos para seleccionar material de televisión”, en Panorama de los archivos audiovisuales, Madrid, RTVE.

Póveda-Lopez, I. C.; Caldera-Serrano, J.; Polo-Carrión, J. A. (2010), "Defining the object of work and conceptualizing TV Audiovisual Information Systems", en Investigación Bibliotecológica, vol. 24, núm. 50, pp. 15-34.

Saavedra Bendito, Pau (2011), Los documentos audiovisuales, ¿qué son y cómo se tratan?, Gijón, TREA. 